\title{
LANGUAGE IDENTIFICATION USING G-LDA
}

\author{
Shubham Saini ${ }^{1}$, Bhavesh Kasliwal ${ }^{2}$, Shraey Bhatia ${ }^{3}$ \\ ${ }^{1,2,3}$ Student, School of Computing Science and Engineering, Vellore Institute of Technology, India, \\ shubham.saini2010@vit.ac.in,bhavesh.kasliwal2010@vit.ac.in, shraey.bhatia2010@vit.ac.in
}

\begin{abstract}
Language Identification has an important role in Natural Language processing applications as one of the pre-processing steps. There are various mechanisms in use today to achieve this task with brilliant recognition rates.

Recent years have seen rapid growth in international communication which has lead to the requirement of systems capable of correctly identifying languages of documents. Possible applications of language identification include information retrieval, web crawlers, text mining and email filtering.
\end{abstract}

The paper uses a process called G-LDA [1], which takes concepts from Latent Dirichlet Allocation (LDA) and Genetic Evolution techniques. This involves framing a set of words having a high frequency of occurrence in any given document. The method was tested on Leipzig Corpora. The phrases that were evolved through the generations reflected significant improvement.

Keywords: Language Identification, Latent Dirichlet Allocation, Gibbs Sampling, Genetic Algorithm, Topic Modeling, Breeding, Fitness, Roulette Wheel.

\section{INTRODUCTION}

Language Identification is the problem of automatically identifying the language a document is written in through the use of computer. Language Identification has an important role in Natural Language processing applications as one of the pre-processing steps.

Recent years have seen rapid growth in international communication which has lead to the requirement of systems capable of correctly identifying languages of documents. Also, with the spread of world-wide Internet access, text is available in a great number of languages other than English. Automatic processing of these texts for purposes like web crawling, reading aids, indexing etc. need a preliminary identification of the language used. Likewise, any system involving dictionary access must identify language before applying any languagespecific operations.

The paper uses a process called G-LDA, which takes concepts from Latent Dirichlet Allocation [2] (LDA) and Genetic Evolution techniques. This involves framing a set of words having a high frequency of occurrence in any given document. The method was tested on Leipzig Corpora. The phrases that were evolved through the generations reflected significant improvement.

LDA is a way of automatically discovering topics within a documents collection. Each word in the documents collection will belong to a particular topic. The technique can be applied to a language identification corpus. The result will be a set of words having a high probability of occurrence within any given document.

Further, set of words generated earlier are subjected to genetic evolution techniques. This is done to get an improved set of words with a higher probability of occurrence within a document.

It was found that the method worked well without any preprocessing like tokenization, unlike the $\mathrm{N}$-Gram based approach [7], and can handle e.g. Arabic documents and documents encoded in Unicode.

Also, the method is very easy to understand and implement, unlike the PPM approach [8], with almost similar detection rates.

\section{SET GENERATION}

A sub-set of sentences from Leipzig Corpora was taken. The languages chosen were Arabic, English, Guajarati, Hindi and Italian. All the sentences from these five languages were combined into a single document and sets of words from these documents were generated using the JGibbLDA [3] package. JGibbLDA is a Java implementation of LDA using Gibbs Sampling technique. A total of 5 sets with 200 words each were generated, each set representing a single language. 
Now, for each word in each language set, the number of lines in the training data for that language matched, $\left(\mathrm{N}_{\mathrm{e}}\right)$ was found. Genetic evolution techniques were applied on the words with $\mathrm{N}_{\mathrm{e}}>0$.

\section{GENETIC EVOLUTION ALGORITHM}

Genetic algorithm was applied as follows:

- Loop for $\mathrm{n}$ generations

$\circ \quad$ Find Fitness Function for each phrase

- Breeding using roulette wheel selection

○ Filtering to produce a new generation

\subsection{Fitness Function}

Based on the number of lines matched, a fitness value is assigned to each phrase:

Fitness $=$ No. sentences containing the phrase $*\left(1+\frac{\mathrm{N}-\mathrm{N}_{\mathrm{w}}}{\mathrm{N}}\right)$

Where

$\mathrm{N}=$ Threshold value

$\mathrm{N}_{\mathrm{w}}=$ No. of words comprising the phrase

Threshold value is taken in order to provide a negative weight. Any phrase containing more than $\mathrm{N}$ words will receive fitness penalty, and phrases with less than $\mathrm{N}$ words receive a bonus.

\subsection{Breeding}

The process used created 1 child from 2 parents using the OR Method. Each survivor from previous generation breeds with a 2nd parent selected using Roulette Wheel Selection.

The OR Method - Take 2 parents, such as (Lottery|Cash) and (Cash/Win), breed them to produce the child (Lottery|Cash|Win). Here, $\mathrm{N}_{\mathrm{w}}=3$ as the phrase comprises of 3 words.

Roulette Wheel Selection - It is a method for choosing a phrase from the breeding pool. Phrases with better fitness are more likely to be chosen.

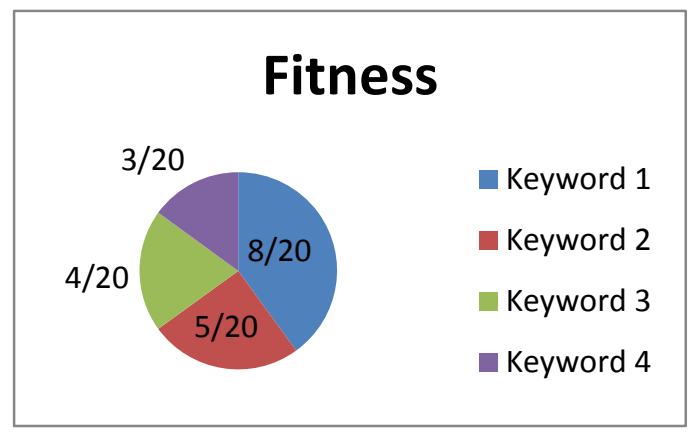

Chart -1: Roulette Wheel Selection
In Chart 1 , the breeding pool consists of 4 phrases. The probability of Phrase 1 being selected is $8 / 20$, the highest among all the phrases. This is based on the fact that Phrase 1 has the highest fitness of 8 .

Breading is carried out as follows to produce new children

- Mark all Phrases as 'new'

- Loop till no phrase is marked 'new'

- Take a phrase (P1) with highest fitness which is marked 'new'.

- Mark P1 as 'old'

- Take another phrase (P2) using Roulette Wheel Selection

- Mark P2 as 'old'

- Breed P1 and P2 to produce a child $\mathrm{C}=$ (P1|P2).

- Mark C as 'old'

\subsection{Filtering}

Once breeding is done, fitness of the newly generated children is calculated and then filtering is performed in order to remove low fitness words. The words remaining after filtering constitute the new generation.

Filtering criteria may vary with need and situation. For the purpose of language identification, it was intended to keep only top 200 phrases. Hence, after each round of breeding, top 200 phrases were sent to the next generation and the rest of the words were discarded.

\section{PROOF OF CONCEPT}

In the Fitness function, as the threshold value $(\mathrm{N})$ increases, the time required to find the number of sentences for each phrase increases with each generation as phrases with more number of words tend to survive. After performing several tests, the threshold value was chosen to be 5. This is the optimum value which balances the time required for finding the number of sentences for each phrase and the number of new generations required. The breeding is stopped when the increase in the fitness of the phrases become insignificant.

The top 10 phrases of the first two generations for the five languages, with their fitness score is given below:

Table -1: Top 10 Arabic language phrases with fitness values

\begin{tabular}{|c|c|c|c|}
\hline \multicolumn{2}{|c|}{ Generation 0} & \multicolumn{2}{|c|}{ Generation 1} \\
\hline 9 & 124.7579956 & g & 124.758 \\
\hline في & 101.0699997 & و ;فقد & 113.152 \\
\hline من & 87.17399597 & في & 101.07 \\
\hline على & 54.66600037 & في;||متحدة & 96.81601 \\
\hline أن أن & 47.12400055 & على;أن & 90.48 \\
\hline
\end{tabular}




\begin{tabular}{|c|c|c|c|}
\hline ان & 38.14199829 & من & 87.174 \\
\hline عن & 33.28199768 & من;دول & 83.888 \\
\hline مع & 30.23999977 & على & 54.666 \\
\hline لـ بـي & 27.395998 & عنز;إى & 52.512 \\
\hline إلى تي إلى & 25.79399872 & مع;لا & 49.504 \\
\hline
\end{tabular}

Table -2: Top 10 English language phrases with fitness values

\begin{tabular}{|l|r|l|r|}
\hline \multicolumn{2}{|c|}{ Generation 0 } & \multicolumn{2}{c|}{ Generation 1 } \\
\hline an & 91.27799988 & year;named & 145.474 \\
\hline of & 85.03200531 & a; had & 140.576 \\
\hline and & 80.85599518 & However;Last & 140.182 \\
\hline to & 73.9980011 & the;two & 117.312 \\
\hline be & 39.94200134 & and;with & 94.496 \\
\hline is & 36.45000076 & an & 91.278 \\
\hline for & 33.13799667 & an;do & 90.35201 \\
\hline was & 31.12199974 & of & 85.03201 \\
\hline de & 27.59399986 & to;so & 82.96 \\
\hline with & 25.45199966 & and & 80.856 \\
\hline
\end{tabular}

Table -3: Top 10 Guajarati language phrases with fitness values

\begin{tabular}{|l|r|l|r|}
\hline \multicolumn{2}{|c|}{ Generation 0 } & \multicolumn{2}{c|}{ Generation 1 } \\
\hline છે & 80.7480011 & છે;અને & 232.33 \\
\hline જ & 80.40599823 & કે;હતી & 180.068 \\
\hline આ & 77.45400238 & આ;છે. & 126.192 \\
\hline ન & 64.80000305 & છે;એ & 112.64 \\
\hline છે. & 64.51199341 & જ;કરવા & 84.81601 \\
\hline એ & 45.97199631 & છે & 80.748 \\
\hline તે & 40.12199783 & $\xi$ & 80.748 \\
\hline અન & 37.96199799 & જ & 80.406 \\
\hline કે & 35.7840004 & આ & 77.454 \\
\hline પણ & 26.51399994 & ન & 64.8 \\
\hline
\end{tabular}

Table -4: Top 10 Hindi language phrases with fitness values

\begin{tabular}{|l|r|l|r|}
\hline \multicolumn{2}{|c|}{ Generation 0 } & \multicolumn{2}{c|}{ Generation 1 } \\
\hline के & 98.9280014 & है; प्रति & 216.79 \\
\hline न & 97.91999817 & हैं;उस & 170.534 \\
\hline
\end{tabular}

\begin{tabular}{|l|r|l|r|} 
है & 93.31200409 & कहा;उन्हें & 159.642 \\
\hline में & 87.01200104 & में;की & 140.56 \\
\hline की & 71.11799622 & न;हो & 116.704 \\
\hline व & 67.98599243 & को;का & 108.96 \\
\hline को & 62.22599792 & के & 98.928 \\
\hline का & 60.35400009 & न & 97.92 \\
\hline कि & 59.84999847 & है & 93.312 \\
\hline
\end{tabular}

Table -5: Top 10 Italian language phrases with fitness values

\begin{tabular}{|l|r|l|r|}
\hline \multicolumn{2}{|c|}{ Generation 0 } & \multicolumn{2}{c|}{ Generation 1 } \\
\hline di & 105.1920013 & che;a & 161.056 \\
\hline in & 73.56599426 & anni;uno & 147.448 \\
\hline del & 72.46799469 & di;ha & 124.768 \\
\hline che & 51.02999878 & di & 105.192 \\
\hline da & 44.51399994 & in;da & 104.96 \\
\hline su & 36.18000031 & in & 73.56599 \\
\hline o & 36.16199875 & del;l & 73.296 \\
\hline ha & 35.17200089 & del & 72.46799 \\
\hline e & 34.0019989 & su;della & 57.168 \\
\hline è & 34.0019989 & che & 51.03 \\
\hline
\end{tabular}

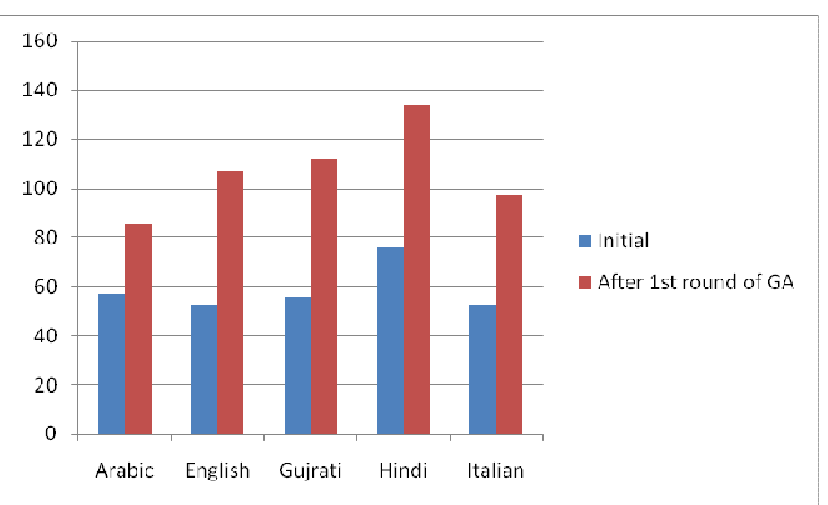

Chart -2: Average Fitness of Top 10 phrases of each language

It is evident from Chart 2 that average fitness of the phrases increases after applying the genetic algorithm.

To check the effectiveness of the evolved phrases, the following method was adopted. The algorithm returns the language of a document $\mathrm{D}$ :

- $\quad$ For Each Language $\mathrm{L}_{\mathrm{i}}$

- $\quad$ For each phrase $\mathrm{K}_{\mathrm{i}} \in \mathrm{L}_{\mathrm{i}}$ 
- $\quad \mathrm{S}\left(\mathrm{L}_{\mathrm{i}}\right)=\sum \mathrm{C}\left(\mathrm{K}_{\mathrm{i}}\right)$

- $C\left(K_{i}\right)=$ No. of lines of D containing $K_{i}$

- $\quad$ Return L, where $\mathrm{S}(\mathrm{L})=\operatorname{Max}(\mathrm{S}(\mathrm{Li}))$

This technique was applied to 15 web-pages of the 5 training languages (Arabic, English, Gujarati, Hindi and Italian). The system was able to identify the language for every web page correctly (giving 100\% recognition rate).

It maybe be noted that the technique was applied to moderate ( $\geq 1000$ words) sized web-pages. The identification rate may decrease when applied to very small sized documents $(<100$ words). However, this can be improved by taking a bigger training data, and retaining more words after each breeding stage.

\section{CONCLUSIONS}

Combining the Genetic evolution technique, which simulates processes of nature, with topic modeling method, the set of phrases generated effectively identify the language of a document.

This technique, when applied to 15 web-pages of the 5 training languages (Arabic, English, Gujarati, Hindi and Italian), was able to identify the language for every web page correctly (giving $100 \%$ recognition rate).

\section{REFERENCES}

[1]. Shubham Saini, Bhavesh Kasliwal and Shraey Bhatia. "Spam Detection using G-LDA" International Journal of Advanced Research in Computer Science and Software Engineering 3.10 (2013).

[2]. Blei, David M., Andrew Y. Ng, and Michael I. Jordan. "Latent dirichlet allocation." the Journal of machine Learning research 3 (2003): 993-1022.J. Breckling, Ed., The Analysis of Directional Time Series: Applications to Wind Speed and Direction, ser. Lecture Notes in Statistics. Berlin, Germany: Springer, 1989, vol. 61.

[3]. Phan, Xuan-Hieu, and Cam-Tu Nguyen. "Jgibblda: A java implementation of latent dirichlet allocation (lda) using gibbs sampling for parameter estimation and inference." (2006).

[4]. Ramage, D., and E. Rosen. "Stanford topic modeling toolbox." (2011).

[5]. Wall, Matthew. "GAlib: A C++ library of genetic algorithm components."Mechanical Engineering Department, Massachusetts Institute of Technology 87 (1996): 54.

[6]. Kranig, Simon. "Evaluation of language identification methods." Bakalárska práca, Universität Tübingen, Nemecko (2005)

[7]. Cavnar, William B., and John M. Trenkle. "N-gram-based text categorization." Ann Arbor MI 48113.2 (1994): 161-175.

[8]. Teahan, William J., and David J. Harper. "Using compression-based language models for text categorization."
Language Modeling for Information Retrieval. Springer Netherlands, 2003. 141-165

\section{BIOGRAPHIES}

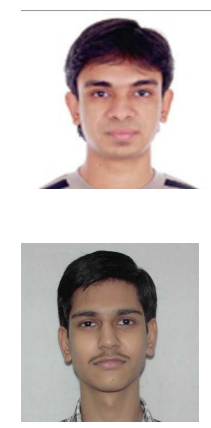

Shubham Saini is a senior year undergraduate student majoring in Computer Science and Engineering. His research interests are Information Retrieval, Semantic Web and Knowledge Discovery in Databases.

Bhavesh Kasliwal is a senior year undergraduate student majoring in Computer Science and Engineering. His research interests are Algorithm Design and Analysis, Data Analytics.

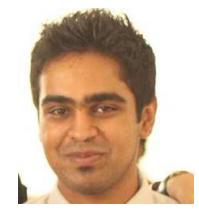

Shraey Bhatia is a senior year undergraduate student majoring in Computer Science and Engineering. His research interests are Information Security and Cryptography. 